\title{
Humerus içten güvenli kilitlemeli çivi
}

\section{Humerus internal safe locking nail}

\author{
Fuat Akpınar \\ İstanbul Medeniyet Üniversitesi Tıp Fakültesi, Ortopedi ve Travmatoloji Ana Bilim Dalı, İstanbul
}

\begin{abstract}
Mevcut buluş, humerus kırıklarında kullanılmak için geliştirilmiş bir çivi yapılanması ile ilgilidir. Buluş, bilhassa kılavuz veya floroskopi kullanmadan ve radial, median ve muskülokutanöz sinirleri yaralamadan güvenli distal kilitleme sağlayan çivileme sistemi ile ilgilidir. Buluş, distalindeki $5^{\circ}-40^{\circ}$ 'lik anterior eğimi sayesinde olekranon fossanın proksimaline kadar kolay ilerletilebilmesine ve rotasyonel stabiliteye katkıda bulunan intramedüller bir çivi ve aynı kesi içerisinden çivinin iç kısmına proksimalden vidalanan ve takiben çivi distal posteriorundaki oval delikten çıkarak distal kilitlemeyi sağlayan pim sistemi (Endopin) ve bunların yardımcı aparatlarını içermektedir. Konuyla ilgili klinik, biyomekanik ve anatomik kadavra çaIışmaları ile, humerus kırığının tespitinde içten kilitlemeli humerus çivisinin güvenle uygulanabildiği ve yeterli stabilite sağladığı gösterilmiştir.
\end{abstract}

Anahtar sözcükler: humerus kırığı; çivi; içten kilitli; güvenli

\section{Amerikan Patent Kurumu (United States Patent Trademark} Office)'na Patent Belgesi için Başvuru Bilgileri[1]

Başvuru bilgileri Tablo 1'de gösterilmiştir. ${ }^{[1]}$

Tablo 1. Başvuru bilgileri ${ }^{[1]}$

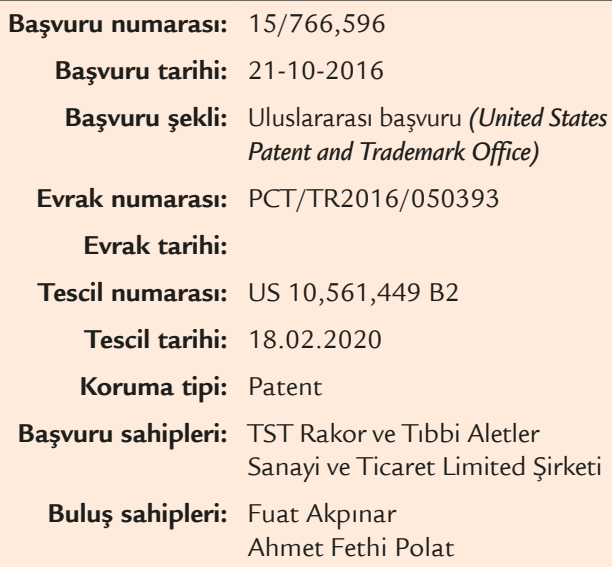

The present invention relates to an improved nail structure for use in humerus fractures. In particular, the invention relates to a nailing system that provides safe distal locking without using a guide or fluoroscopy and without injuring the radial, median and musculocutaneous nerves. The invention is an intramedullary nail that contributes to the rotational stability and easy advancement to the proximal of the olecranon fossa thanks to its distal anterior inclination of $5^{\circ}-40^{\circ}$, and the pin system (Endopin) that is screwed from the proximal to the inner part of the nail through the same incision and then exits from the oval hole in the distal posterior of the nail (Endopin) and It includes their auxiliary apparatus. With the clinical, biomechanical and anatomical cadaver studies on the subject, it has been shown that the humerus internal locking nail can be applied safely and provide sufficient stability in the fixation of humeral fractures.

Key words: humerus fracture; nail; internal locking; safe

\section{Teknik Alan ${ }^{[1]}$}

"Mevcut buluş, humerus kırıklarında kullanılmak için geliştirilmiş bir çivi yapılanması ile ilgilidir."

\section{Önceki Teknik/Teknikler ${ }^{[1]}$}

"Humerus kırıkları, sıklıkla trafik veya herhangi bir kazada el üzerine düşme sonucu görülen yaygın kırıklardır. Her 20 kırıktan biri humerus kırığıdır. Humerus kırıklarının cerrahi tedavisinde intramedüller çiviler kullanılabilmektedir.

Mevcut uygulamalarda, intramedüller çivileme sırasında distal kilitleme için kılavuz veya floroskopi kullanımı gerektiğinden hasta radyasyona maruz kalmaktadır. Ayrica, humerusun distal kilitlenmesi için ekstra bir cilt kesisinin yapılması enfeksiyon gelişme riskini artırmaktadır. Gerek ekstra cilt kesisi, gerekse distal vida gönderilmesi sırasında damar-sinir yaralanma riskinin artması mevcut uygulamaların diğer dezavantajları arasındadır.

- Illetişim adresi: Prof. Dr. Fuat Akpınar, S.B. Göztepe Prof. Dr. Süleyman Yalçın Şehir Hastanesi, Ortopedi ve Travmatoloji Kliniği, İstanbul Tel: 0546 - 6368801 e-posta: fuatakpinar@yahoo.com ORCID iD: 0000-0001-9399-8516

- Geliș tarihi: 8 Kasım $2020 \quad$ Kabul tarihi: 19 Kasım 2020 
CN104323847 numaral, A61517/72 IPC kodlu Çin Patent başvurusunda, humerus kırıklarında kullanılan kilitlemeli bir çividen bahsedilmektedir. Ancak, bu çivide distal kısımda kilitlemenin gerçekleştirilebilmesi için ek kesi yapılması gerektiğinden buradaki yaşanabilecek olumsuzluklara dair bir çözüm getirilmemekte ve distal kilitleme bölgesindeki olası radial, median ve muskulokutanöz sinir yaralanmaları, artan enfeksiyon riskleri ve uzayan iyileşme süreleri riski devam etmektedir."

\section{Buluşun Kısa Tarifi ${ }^{[1]}$}

"Yukarıda anlatılan istenmeyen durumların üstesinden gelebilmek üzere, buluşun amaçları;

- Çivinin distal kısmında olası bir kesi yapılmasına gerek kalmadan içten dışarıya doğru bir kilitleme yapılmasıdır.

- Uygulama sırasında klavuz veya floroskopi kullanilma gereksiniminin ortadan kaldırılmasıdır.

- Uygulama ve ameliyat süresinin kısaltılmasıdır. Bu şekilde, tedavi süresi kısalmasına da önemli bir katkı sağlanmasıdır.

- Distal kilitleme bölgesinde olası radial, median ve muskulokutanöz sinir yaralanmalarının ortadan kaldırılmasıdır.

Bahsedilen amaçlara ulaşmak üzere, birçok avantajlar sağlayan humerus içten güvenli kilitlemeli çivi geliştirilmiştir. Buluş, distalindeki $5^{\circ}-40^{\circ}$ 'lik anterior eğimi sayesinde olekranon fossanın proksimaline kadar kolay ilerletilebilmesine ve rotasyonel stabiliteye katkıda bulunan intramedüller bir çivi ve aynı kesi içerisinden çivinin iç kısmına proksimalden vidalanan ve takiben çivi distal posteriorundaki oval delikten çıarak distal kilitlemeyi sağlayan pim sistemi (Endopin) ve bunların yardımcı aparatlarını içermektedir.

Buluş sayesinde, distal kısımda kilitlemenin gerçekleştirilebilmesi için ek kesi yapmadan, klavuz ve floroskopi kullanmadan, ameliyat süresini uzatmadan, distal kilitleme bölgesinde radial, median ve muskulokutanöz sinir yaralanmaları yapmadan, enfeksiyon riskini artırmadan, iyileşme süresini uzatmadan çivileme yapılabilmektedir."

\section{Buluşun Detaylı Açıklanması [1]}

"Referans Numaraları[1]: (1)-Humerus içten güvenli kilitlemeli çivi (humerus insafelock nail), (2)-Kilitleme pimi, (3)-Kilitleme pimini gönderici yuvası, (4)-Çivinin kompresyon deliği, (5)-Çivinin kilitleme pimi yuvası, (6)-Çivi proksimalindeki açılı vida deliği, (7)-Kilitleme pimi yivli ucu, (8)-Çivinin alt (distal) deliği, (9)-Kilitleme piminin kemiğe giriş ucu, (10)-Çivinin distal kısmındaki anatomik açılı ucu, (11)-Kilitleme piminin yivli proksimal kısmı, (12)-Çivinin dönmeyi engelleyici uçyapısı, (13)-Üst kısım, (14)-Alt kısım, (15)-Çivi proksimalindeki vida delikleri.
Buluşumuz, Şekil 1 ve 2'de belirtildiği üzere; humerus içten güvenli kilitlemeli çivi (1) olup, iç kısmına monte edilen ve distal kısımdan kilitleme sağlayan kilitleme pimi (2) oluşturulmuştur. Üst kısımda (13) çivinin kompresyon deliği (4), çivinin kilitleme pimi yuvası (5), çivi proksimalindeki açılı vida delikleri (6) bulunur. İçten kilitleme pimi (2) üzerinde kilitleme pimini gönderici yuvası (3) üzerinden tornavida ile ilerleyerek alt kısımdaki (14), çivinin alt (distal) deliğinden (8) çıkan kilitleme pimi yivli uç (7) üzerindeki kilitleme piminin kemiğe giriş ucundan (9) humerus kemiği distalinde vidalanarak kilitleme yapmaktadır. Humerus içten güvenli kilitlemeli çivi (1) alt kısmında (14), çivinin dönmeyi engelleyici uç yapısı (12), çivinin alt (distal) deliği (8) bulunur. Çivinin dönmeyi engelleyici uç yapısı (12) ile kilitleme piminin kemiğe giriş uсu (9) arasında oluşturulan açı ile humerus içten güvenli kilitlemeli çivi (1) üzerinde çivinin distal kısmındaki anatomik açılı иси (10) bulunmaktadır.

Humerus içten güvenli kilitlemeli çivimiz (1), proksimal (üst) humerus ve diyafizer (şaft) humerus kırıklarında kullanılabilmektedir.

Humerus içten güvenli kilitlemeli çivinin (1) diğer sistemlere üstünlük sağlayan özellikleri şu şekildedir:

Să̆ ve sol humerus için aynı humerus içten güvenli kilitlemeli çivi (1) kullanılabilmektedir.

Humerus kemiği distalinde (alt uç) yer alan olekranon fossanın (olekranon anatomik çukurluğu) üstünde kalacak şekilde, en distale (alt uç) kadar yerleştirilebilmektedir.

Distal (alt uç) kilitleme için kılavuz veya floroskopi (X-ışını yayan cihaz) kullanımı gerekmemektedir. Bu şekilde hastanın üzerinde oluşacak olumsuz etkiler azaltılmaktadır.

Distal (alt uç) kilitleme klasik bilinen sistemlerde olduğu gibi, çivinin üzerindeki vida deliğinden geçen vida ile yapılmamaktadır. Humerus içten güvenli kilitlemeli çivide (1), distal kilitleme içeriden dışarıya doğru vidalanarak yapılır. Humerusun distal bölümünde kilitleme için cilt kesisi yoktur. $\mathrm{Bu}$ durum estetik avantaj sağlar. Adele, tendon ve fasia hasarlanması olmaması ise fonksiyonel önemli bir avantajıdır.

Klasik bilinen sistemlerdeki distal kilitleme bölgesinde seyreden radial, median ve muskulokutanöz sinir yaralanmalarının önüne geçilmiştir.

Uygulama süresi kısa olup, ameliyat süresi azaltılmıştır.

Humerus içten güvenli kilitlemeli çivinin (1) uygulama şekli:

Kırık humerus bölümünün redüksiyonu (kemiğin anatomik pozisyonunun yeniden kazandırıması) tamamlandıktan sonra öncelikle humerus içten güvenli kilitlemeli çivi (1) uygun giriş yerinden kemik kanalına yerleştirilir. Kırık hattını geçerek final pozisyonu olan humerusun en distalinde (alt uç) yer alan olekranon fossa'nın (çukurun) $25 \mathrm{~mm}$ kadar üzerinde sonlanır. Humerus içten güvenli kilitlemeli çivimiz (1) uzun çivi olduğu için humerusun kanalı boyunca yerleştirilir. 
Humerus içten güvenli kilitlemeli çivi (1) yerleştirilirken humerus içten güvenli kilitleme çivisinin (1) distal kısmındaki $5^{\circ}-40^{\circ}$ arasında çivinin distal kısmındaki anatomik açılı uç (10) humerusun anterior yüzüne bakar. Bu çivinin distal kısmındaki anatomik açılı uç (10) formu ve humerus içten güvenli kilitlemeli çivinin (1) buradaki çivinin dönmeyi engelleyici uç yapısı (12), humerus içten güvenli kilitlemeli çivinin (1) kanal içinde distale (aşağıya) kolay ilerletilebilmesini sağlamakta ve oluşabilecek rotasyonel (dönme) hareketlerini engellemektedir.

Humerus içten güvenli kilitlemeli çivi (1) bu şekilde kanal içine yerleştirildiğinde, çivinin ikinci komponenti olan kilitleme pimi (2), humerus içten güvenli kilitlemeli çivi (1) içerisinden kilitleme pimi gönderici yuvası (3) kullanılarak gönderilir.

Kilitleme piminin (2) kemiğe girebilen sivri formdaki kilitleme piminin kemiğe giriş иси (9), humerus içten güvenli kilitlemeli çivi (1) distalinde yer alan çivinin alt deliğinde (8) tercihen en distal uçtan 20-60 mm yukarıda çıkarak posterior (arka) yöne gelecek şekilde kemiğe açılı olarak saplanır ve vidalanarak kilitlenir. Kilitleme piminin (2) üzerindeki kilitleme pimi yivli ucu (7) bu ilerleme ve saplanmayı kolaylaştırmaktadır.

Bu şekilde humerus kemiğinin distal bölümünde istenen sıkı tespit, humerus içten güvenli kilitlemeli çivisinin (1) alt kısmındaki (14) $5^{\circ}-40^{\circ}$ arasında çivinin distal kısmındaki anatomik açılı uçun (10) humerusun anterior yüzünü sıkıştırması ve kilitleme piminin (2), humerus içten güvenli kilitlemeli çivi (1) distalindeki çivinin alt deliğinden (8) çıkarak posterior yöne gelecek şekilde kemiğe saplanması ve vidalanması ile elde edilmektedir.

Kilitleme piminin yivli proksimal kısmı (11), humerus içten güvenli kilitlemeli çivi (1) proksimalinde yer alan çivinin kilitleme pimi yuvası (5) ile eşleşmiş olduğundan final pozisyonunda buraya kilitlenmiştir.

Proksimal kilitleme aşamasında ise eğer kırık hattında kapatılması gereken bir boşluk var ise (kompresyon ihtiyacı), distal kilitlemeyi takiben humerus içten güvenli kilitlemeli çivinin (1) kompresyon deliğine (4) bir adet vida geçilir ve sonrasında humerus içten güvenli kilitlemeli çivi (1) tepesinden kompresyon vidası göndermek suretiyle muhtemel kırık hattındaki boşluk komprese edilir. Gerekli ise ya da öncelikli olarak humerus içten güvenli kilitlemeli çivi (1) proksimalindeki $0^{\circ}-20^{\circ}$ oblik açılı, proksimalindeki açılı vida delikleri (6) kullanilabilir.

Humerus içten güvenli kilitlemeli çivinin (1) alternatif bir yapılanmasında, üst kısmında (13), proksimal bölümünde farklılık oluşturulmuştur. Distal kilitlemenin tamamlanmasına kadar izlenen yol yukarıda anlatıldığı gibi olmaktadır.

Buradaki fark, Şekil 2'de görüldüğ̈̈̈ üzere, humerus içten güvenli kilitlemeli çivi (1) proksimalindeki $0^{\circ}-30^{\circ}$ açılı çivi proksimalinde vida delikleridir. (15) Buradaki çivi proksimalindeki vida deliklerinden (15) proksimal kilitleme amaçı birbiri ile açı yapacak şekilde vidalar gönderilebilmektedir. Çivi proksimalindeki vida deliklerinin (15) konumu gereği, proksimal kilitleme yapılırken ilave bir cilt kesisi ihtiyacı ortadan kaldırılmıştır.

Humerus içten güvenli kilitlemeli çivinin (1) yerleştirilmesi için yapılan aynı kesi içerisinden vidaların yerleştirilebilmesi săglanmıştır. Bu sayede adele, tendon ve fasia gibi ilave yumuşak doku hasarlanmasının önüne geçilmiştir. Proksimal kilit vidasında gevşeme, migrasyon ve irritasyon oluşumu görülmez. Fonksiyonel ve estetik avantaj elde edilir. Bu sayede, tıpkı distal kilitlemede olduğu gibi kullanımı sırasında ortama $x$-ışını yayan floroskopi cihazı ve kılavuz kullanımı gerekmemektedir. Uygulama süresi dolayısıyla ameliyat süresi kısaltılmaktadır. Hastanın ameliyat sonrası rehabilitasyon süresinde önemli iyileşmeler elde edilmektedir.

Buluşun tercih edilen bir uygulamasında, humerus içten güvenli kilitlemeli çivi (1) iç kısmına boydan boya proksimalden vidalanarak distal kısımdaki çivinin alt deliğinden (8) çıkarak distal kilitlemeyi sağlayan kilitleme pimi (2), distal kısımdan kilitleme sağlayan kilitleme piminin (2) gönderilmesini sağlayan kilitleme pimi (2) üzerinde en az bir kilitleme pimi gönderici yuvası (3), kilitleme piminin (2) humerus içten güvenli kilitlemeli çivi (1) içerisinde ilerlemesini sağlayan humerus içten güvenli kilitlemeli çivi (1) proksimal kısmında en az bir çivinin kilitleme yuvası (5), kilitleme piminin (2) üzerinde en az bir kilitleme piminin yivli proksimal kısmı (11), kilitleme pimi (2) üzerinde, çivinin alt deliğinden çıkarak kilitleme yapan en az bir kilitleme pimi yivli ucu (7), kilitleme pimi yivli ucu (7) üzerinde, kemiğe açılı bir şekilde giriş yapıp kilitleme sağlayan en az bir kilitleme piminin kemiğe giriş uсu (9), humerus içten güvenli kilitlemeli çivi (1) distal kısmında oluşturulan eğ̈imli ve düzlenmiş yapıda çivinin distal kısmındaki anatomik açılı uсu (10), humerus içten güvenli kilitlemeli çivi (1) distal kısmında çivinin dönmeyi engelleyici uç yapısı (12) içeren humerus içten güvenli kilitlemeli çivi (1) oluşturulmuştur.

Kilitleme pimini gönderici yuvası (3) üzerinden tornavida ile ilerleyerek alt kısımdaki (14) çivinin alt deliğinden (8) çıkan kilitleme pimi yivli uси (7) üzerinde kemiği distalinde vidalanarak kilitleme yapan kilitleme piminin kemiğe giriş иси (9) içerir.

Humerus içten güvenli kilitlemeli çivi (1) distal kısmında, kemiğe girmeyi kolaylaştıran, aşağıya doğru eğimli, üstü düzlenmiş $5^{\circ}-40^{\circ}$ açılı yapıda çivinin distal kısmındaki anatomik açılı uсu (10) bulunur.

Humerus içten güvenli kilitlemeli çivisinin (1) üst kısmında (13) $0^{\circ}-20^{\circ}$ açılı çivi proksimalindeki açılı vida delikleri (6) bulunur.

Üst kısımda (13) kemiğe kilitleme ve kırık kısmın kompresyonu için oluşturulmuş kompresyon deliği (4) oluşturulmuştur. 
Kilitleme piminin (2) üzerinde kilitleme piminin yivli proksimal kısmı (11), kilitleme piminin yivli proksimal kısmı (11) ile eşlenmiş pozisyonunda olmasını sağlayan humerus içten güvenli kilitlemeli çivi (1) üst kısmında (13) çivinin kilitleme pimi yuvası (5) bulunur.

Humerus içten güvenli kilitlemeli çivisinin (1) alt kısmında (14), humerusun anterior yüzünü sıkıştırması ve kilitleme piminin (2), humerus içten güvenli kilitlemeli çivi (1) alt kısmındaki (14) çivinin alt deliğinden (8) çıkarak posterior yöne gelecek şekilde kemiğe içeriden dışarıya doğru açılı olarak saplanmasını ve vidalanarak kilitlenmesini sağlayan kilitleme pimi (2) üzerinde kilitleme pimi yivli uси (7) içerir.

Humerus içten güvenli kilitlemeli çivisinin (1) alt kısmında (14) kemiğe girişi kolaylaştıran çivinin distal kısmındaki anatomik açılı иси (10) üzerinde çivinin dönmeyi engelleyici uç yapısı (12) bulunur.”

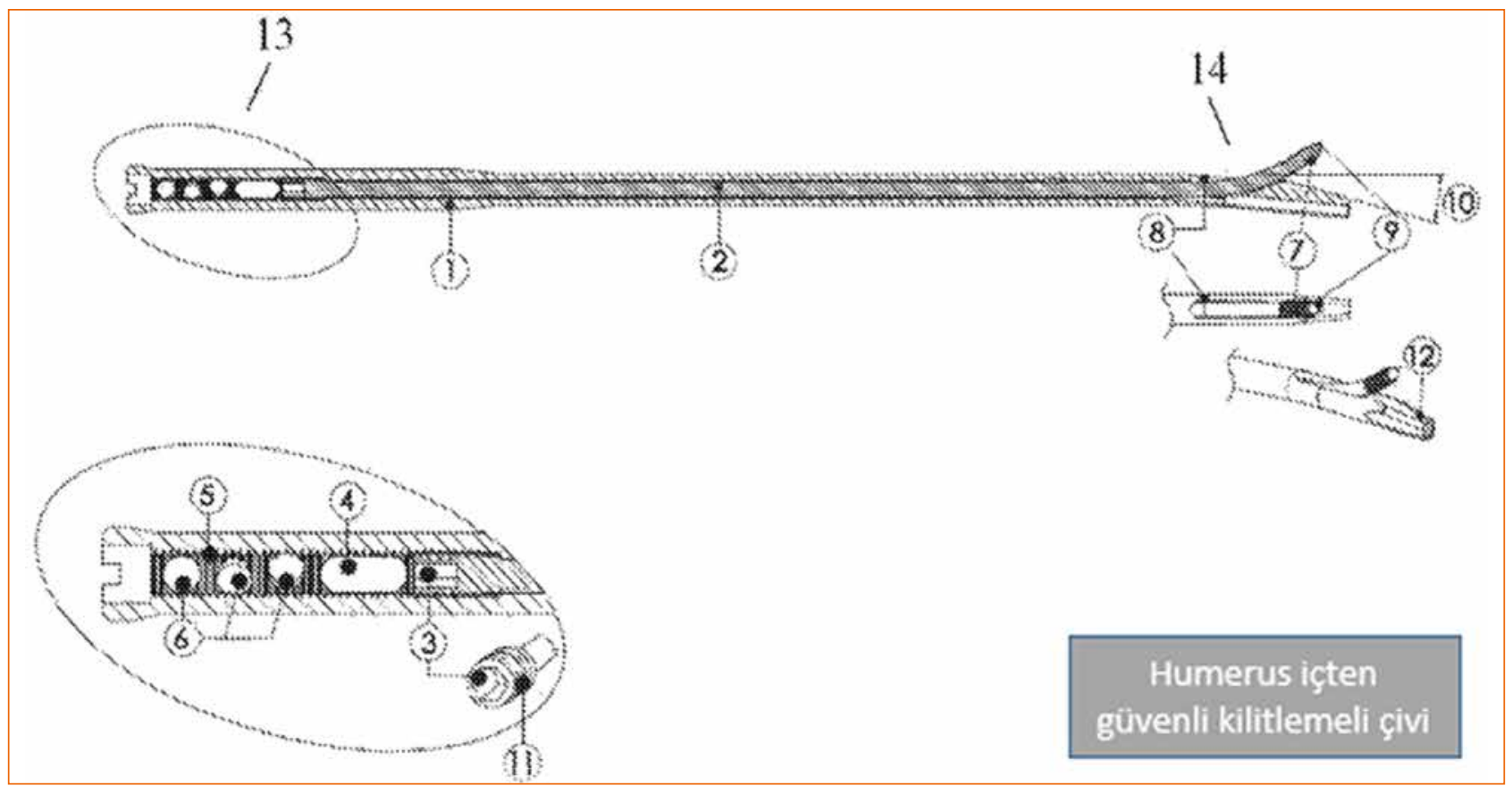

Şekil 1. Buluşun temsili bir uygulamasının çizimidir. ${ }^{[1]}$

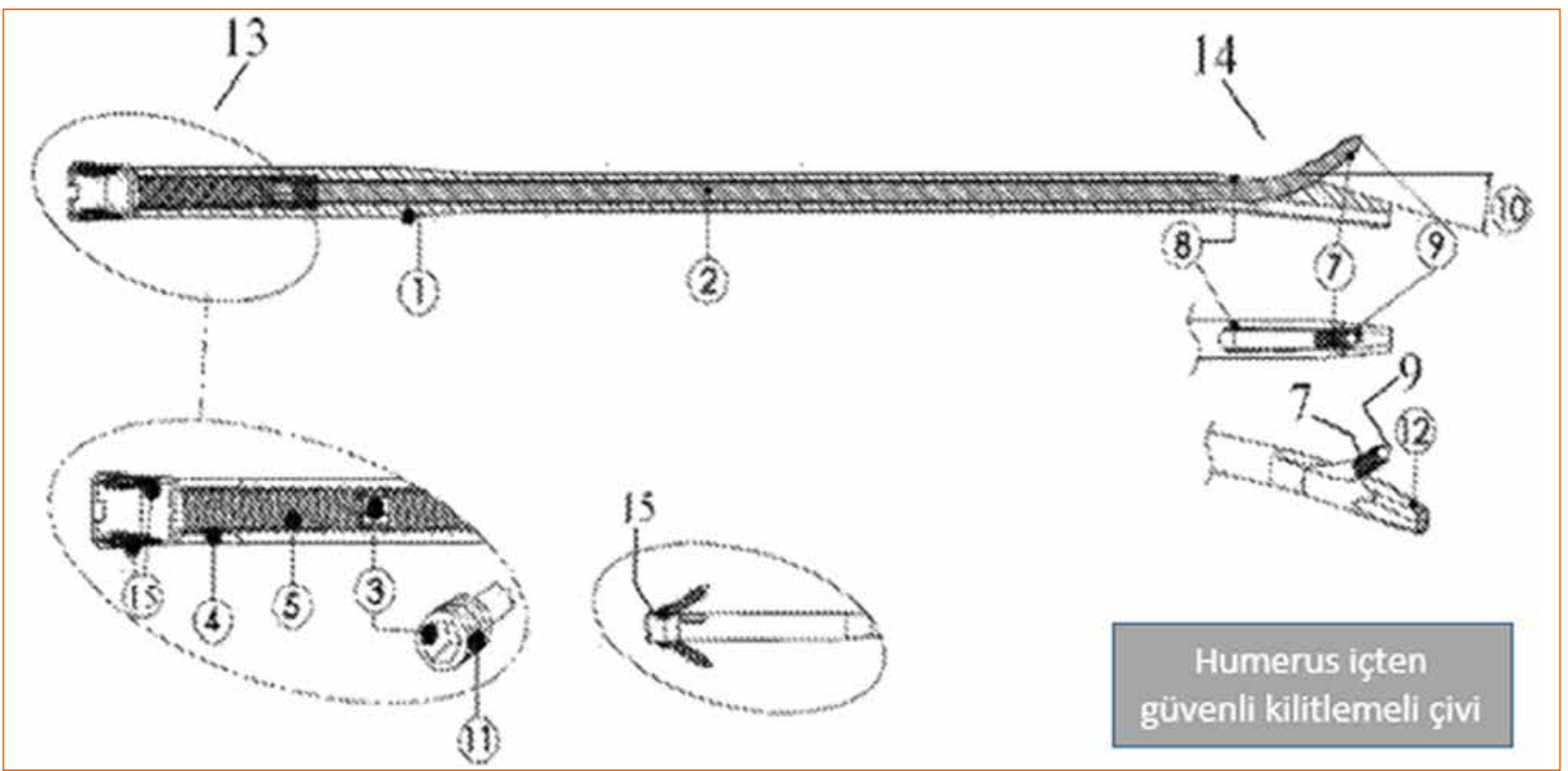

Şekil 2. Buluşun temsili bir diğer uygulamasının çizimidir. ${ }^{[1]}$ 


\section{İstemler ${ }^{[1]}$}

1. Buluş, humerus kınklarının cerrahi tedavisinde kullanılan çiviler ile ilgili olup, özelliği;

- humerus içten güvenli kilitlemeli çivinin (1) yerleştirilmesi için yapılan aynı kesi içerisinden vidaların humerus içten güvenli kilitlemeli çivi (1) iç kısmına boydan boya proksimalden vidalanarak ve takiben çivinin alt deliğinden (8) çıkarak distal kilitleme bölgesinde seyreden radial, median ve muskulokutanöz sinir yaralanmalarının önüne geçerek, distal kilitleme için kılavuz veya floroskopi kullanımı gerekmeden distal kilitlemeyi sağlayan kilitleme pimi (2),

- distal kısımdan kilitleme sağlayan kilitleme piminin (2) gönderilmesini sağlayan kilitleme pimi (2) üzerinde en az bir kilitleme pimini gönderici yuvası (3),

- kilitleme piminin (2) humerus içten güvenli kilitlemeli çivi (1) içerisinde ilerlemesini, kilitleme piminin yivli proksimal kısmı (11) ile eşlenmiş pozisyonunda olmasını sağlayan humerus içten güvenli kilitlemeli çivi (1) üst kısmında (13) humerus içten güvenli kilitlemeli çivi (1) proksimal kısmında en az bir çivinin kilitleme pimi yuvası (5),

- kilitleme piminin (2) üzerinde en az bir kilitleme piminin yivli proksimal kısmı (11),

- kilitleme pimi (2) üzerinde, çivinin alt deliğinden çıkarak kilitleme yapan en az bir kilitleme pimi yivli uси (7),

- kilitleme pimi yivli ucu (7) üzerinde, kemiğe açılı bir şekilde giriş yapıp kilitleme sağlayan kilitleme pimini gönderici yuvası (3) üzerinden tornavida ile ilerleyecek alt kısımdaki (14) çivinin alt deliğinden (8) çıkan kilitleme pimi yivli uси (7) üzerinde humerus kemiği distalinde kilitleme yapan en az bir kilitleme piminin kemiğe giriş uсu (9),

- humerus içten güvenli kilitlemeli çivi (1) distal kısmında oluşturulan eğimli ve düzlenmiş yapıda, kemiğe girmeyi kolaylaştıran, aşă̆ıya doğru eğimli, üstü düzlenmiş $5^{\circ}-40^{\circ}$ açılı yapıda çivinin distal kısmındaki anatomik açılı иси (10),

- humerus içten güvenli kilitlemeli çivi (1) distal kısmında çivinin dönmeyi engelleyici uç yapısını (12) içeren humerus içten güvenli kilitlemeli çivi (1) ile karakterize edilir.

2. İstem 1'e göre humerus içten güvenli kilitlemeli çivi (1) olup, özelliğ;

- humerus içten güvenli kilitlemeli çivisinin (1) üst kısmında (13) $0^{\circ}-20^{\circ}$ açılı çivi proksimalindeki açıı vida delikleri (6) içermesidir.

3. İstem 1'e göre humerus içten güvenli kilitlemeli çivi (1) olup, özelliği;
- üst kısımda (13) kilitleme için birbiri ile açı yapacak şekilde vidaların gönderildiği, $0^{\circ}-30^{\circ}$ açılı çivi proksimalindeki vida delikleri (15) içermesidir.

4. İstem 1'e göre humerus içten güvenli kilitlemeli çivi (1) olup, özelliği;

- üst kısımda (13) kemiğe kilitleme ve kırık kısmın kompresyonu için oluşturulmuş çivinin kompresyon deliği (4) içermesidir.

5. İstem 1'e göre humerus içten güvenli kilitlemeli çivi (1) olup, özelliğ;

- humerus içten güvenli kilitlemeli çivisinin (1) alt kısmında (14), humerusun anterior yüzünü sıkıştırması ve kilitleme piminin (2), humerus içten güvenli kilitlemeli çivi (1) alt kısmındaki (14) çivinin alt deliğinden (8) çıkarak posterior yöne gelecek şekilde kemiğe içeriden dışarıya doğru açılı olarak saplanmasını ve vidalanarak açılı bir biçimde kilitlenmesini sağlayan kilitleme pimi (2) üzerinde kilitleme pimi yivli ucu (7) içermesidir.

6. İstem 1'e göre humerus içten güvenli kilitlemeli çivi (1) olup, özelliğ;

- humerus içten güvenli kilitlemeli çivisinin (1) alt kısmında (14) kemiğe girişi kolaylaştıran çivinin distal kısmındaki anatomik açılı uсu (10) üzerinde çivinin dönmeyi engelleyici uç yapısı (12) içermesidir.

\section{YAZARIN KONUYLA ILGILI ÇALIŞMALARI}

Günümüzde, geleneksel intramedüller çivilerin antegrad yöntemle uygulanması sırasında, humerus distal $1 / 3$ 'ünde medullanın aniden daralması nedeniyle distal ve bazı midshaft kırıklarda uygulama zorluğu, distal kilitleme için yapılan ek kesi nedeniyle damar-sinirtendon hasarı ve enfeksiyon gelişme riskinin artması ve skopi kullanımının radyasyon maruziyetine yol açması bu tedavi yönteminin humerus kırıklarında kullanımını sınırlamıştır. Humerus içten güvenli kilitlemeli çivi, geleneksel kilitli çivilerde yaşanan sorunları gidermek için geliştirilmiş yeni dizayn çivileme sistemidir.

Literatürde, geleneksel kilitleme sistemli çiviler ile içten güvenli kilitlemeli çivinin biyomekanik olarak dayanıklılıklarının karşılaştırıldığı bir çalışmada ${ }^{[2]}$ her iki çivileme sisteminin de aksiyel ve rotasyonel yüklenmelere karşı yeterli stabiliteyi sağladığı gösterilmiştir. Her iki çivileme sisteminin distal kilitlenmesi sırasında kilitleme sürelerinin ve nörovasküler yapılara olan yakınlığının incelendiği bir kadavra çalışmasında ${ }^{[3]}$ ise, içten güvenli kilitlemeli çivinin distal kilitlenmesinin geleneksel çiviye göre daha kısa sürede gerçekleştiği gösterilmiştir. Çalışmada uygulama sırasında her iki çivi sisteminde distal kilitleme sırasında nörovasküler yaralanma olmasa da geleneksel çivilerin radial sinire 
olan yakınlığı gözönüne alındığında içten güvenli kilitlemeli çivinin avantajı vurgulanmıştır. Son olarak, humerus cisim kırıklarında distal içten güvenli kilitlemeli çivilerin distal kilitleme sırasındaki ve sonrasındaki komplikasyonlarını azaltıp azaltmadığını ve distal kilitleme için geçen süreyi inceleyen bir klinik çalışmada ${ }^{[4]}$, hastaların hiçbirinde damar-sinir-tendon yaralanması ve enfeksiyon görülmemiş, ancak \%3,2 sinde çivi uygulaması sırasında anterior kortekste kırık, \%3,2'sinde takipler sırasında çivinin distal kısmında çivi kırılması, \%3,2'sinde takipler sırasında vida gevşemesine bağlı rotasyonel instabilite geliştiği belirtilmiştir. Çalışmada, distal kilitleme için geçen ortalama süre $2,1 \mathrm{dk}$. olarak belirtildikten sonra bu çivinin humerus cisim kırıklarında nörovasküler hasar ve diğer yumuşak doku problemleri olmadan kolaylıkla ve skopi kullanmadan uygulanabileceği ve bu sayede geleneksel çivilerde karşılaşılabilen birçok distal kilitleme sorunlarından kaçınılabileceği vurgulanmıştır.

Sonuç olarak: humerus içten güvenli kilitlemeli çivi ile yapılan ameliyatlarda; klavuz ve skopi kullanmadan, cilt kesisi yapmadan, nörovasküler yaralanma yapmadan, ameliyat süresini uzatmadan distal kilitleme kolaylıkla yapılabilmektedir ve çivinin distal kısmının $5^{\circ}$ 'lik anteriora açılanması sayesinde en distale (olekranon çukurunun proksimaline) kadar kolay ilerletilerek rotasyonel stabiliteye katkı sağlanabilmektedir.

\section{KAYNAKLAR}

1. Humerus Internal Safe Locking Nail. United States Patent and Trademark Office. Patent Certificate. No: 15/766,596. http://patft.uspto.gov/netacgi/nph-Parser?Sect1=PTO1\&Se ct2=HITOFF \&d=PALL\&p=1\&u=\%2Fnetahtml\%2FPTO $\% 2$ Fsrc hnum.htm \& $r=1 \& f=G \& l=50 \& s 1=10,561,449 . P N . \& O S=P N / 10$ $, 561,449 \& R S=P N / 10,561,449$

2. Erden T, Kapicioglu M, Demirtas A, Bilsel K, Akpinar F, Kuduz $\mathrm{H}$. Biomechanical comparison of intramedullary humeral nails with different distal locking mechanisms. Acta Orthop Traumatol Turc 2019;53:490-6. Crossref

3. Tasci M, Turkmen I, Celik H, Akcal MA, Şekerci R, Keles N, Saglam N, Akpinar F. InSafeLock humeral nail provides a safe application for proximal and distal locking screws with distal endopin - An anatomical study. Orthop Traumatol Surg Res 2019;105:1005-11. Crossref

4. Demirtaş A, Uygur ME, Türkmen I, Özkut AT, Akpınar F. Can the complications of distal locking be prevented with a new nail that offers a novel locking technique in the treatment of humeral shaft fractures? Jt Dis Relat Surg 2020;31:470-5. https://www.ncbi.nlm.nih.gov/pmc/articles/PMC7607937/ 